IAC-08-B1.I.1

\title{
ATMOSPHERIC AEROSOL CHARACTERIZATION WITH THE DUTCH-CHINESE FAST FORMATION FLYING MISSION
}

\author{
E. Gill, D. Maessen, E. Laan ${ }^{+}$, S. Kraft*, G. T. Zheng ${ }^{\ddagger}$ \\ Chair of Space Systems Engineering (SSE), Faculty of Aerospace Engineering, Delft University of Technology, \\ Kluyverweg 1, 2629 HS Delft, The Netherlands, e.k.a.gill@tudelft.nl, ph.: +31 (15) 27 87458, fax: +31 (15) 2785322 \\ +TNO Science and Industry, Stieltjesweg 1, 2600 AD Delft, The Netherlands, erik.laan@tno.nl, ph.: +31 (15) \\ 2692723, fax: +31 (15) 2692111 \\ *cosine Research, Niels Bohrweg 11, 2333 CA Leiden, The Netherlands, s.kraft@cosine.nl, ph.: +31 (71) 5284968, \\ fax: +31 (71) 5284963 \\ ${ }^{\ddagger}$ Department of Astronautics and Aeronautics, School of Aerospace Engineering, Tsinghua University, Beijing, China, \\ gtzheng@tsinghua.edu.cn, ph.: +86 (10) 62783235, fax: +86 (10) 82315143
}

\begin{abstract}
Large current uncertainties in the characteristics of aerosols in the Earth's atmosphere preclude meaningful climate model evaluation. The FAST mission will contribute to the characterization of aerosols and their relation to climate change through a synoptic evaluation of local, regional and global aerosol data and altitude profiles of the cryosphere. The Dutch-Chinese mission will implement this objective through a unique combination of payloads onboard of two cooperating micro-satellites flying in formation in a Low-Earth Orbit. The FAST payload suite is unique in that it allows an unprecedented characterization of aerosols through a spectro-polarimeter instrument, which, when combined with radar and laser altimeter data, contributes to the characterization of the indirect climate forcing due to aerosols. Finally, flying instruments on two satellites in formation and, in a later mission phase, in a train configuration, allows an exceptional flexibility to study the temporal and spatial distribution and evolution of aerosols in the Earth's atmosphere.
\end{abstract}

\section{INTRODUCTION}

FAST (Formation for Atmospheric Science and Technology Demonstration) is a mission for the synoptic evaluation of local, regional and global aerosol data and altitude profiles of the cryosphere with cooperating micro-satellites flying in formation in 2011. It originates from a decision of the Tsinghua University, China, and the Delft University of Technology, The Netherlands, to jointly define, develop and operate a space mission which covers scientific objectives, technology demonstration, and educational purposes alike. The complexity of the mission will require a concerted effort from national universities, knowledge and research institutes and industries in both countries.

An improved monitoring and prediction of the Earth's climate requires more and better in-situ measurements on a global scale. In particular, current uncertainties in climate forcings due to aerosols preclude meaningful climate model evaluations. The FAST mission will allow an unprecedented characterization of atmospheric aerosols and their forcings on the climate as well as a monitoring of the evolution of height profiles in the cryosphere. The mission will realize synergies between different data types from the scientific payloads on FAST for improved science return.
The FAST space segment will consist of a spacecraft (FAST-D), being developed in Delft while the other spacecraft (FAST-T) will be developed in Beijing. The space segment architecture will allow for a flexible adaptation of the relative geometry to strengthen observation conditions and maximize data return (formation flying) or resolve temporal atmospheric changes (train configuration). The open architecture offers other countries the possibility to add further satellites to the formation to increase spatial and temporal resolution or to perform synergetic observations.

The scientific payload will comprise two miniaturized spectro-polarimeters and two altimeters. The spectro-polarimeters will be used for the detection and characterization of aerosols with one instrument on each spacecraft. To determine cryospheric height profiles, a laser altimeter will be flown on FAST$\mathrm{D}$ and a radar altimeter on FAST-T. This opens up synergies for enhanced science return in the ground processing and allows, in the case of the altimeters, for the unique opportunity to crosscalibrate and compare the performance of the two instruments. The spectro-polarimeter, together with the radar and laser altimeters will also allow the characterization of indirect aerosol climate forcings which is considered a major scientific return of the mission. 


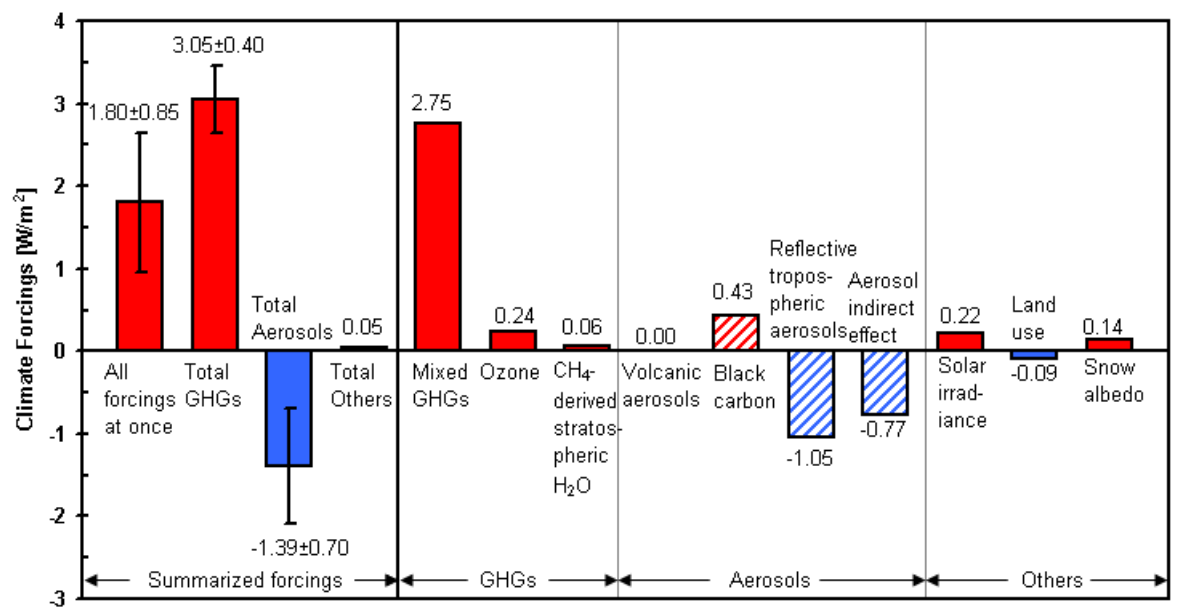

Fig. 1 Effective climate forcings applied to drive the 1880 to 2003 simulated climate change ${ }^{7}$. Left, the summarized forcings are indicated which are detailed (middle and right) for green house gases (GHGs), aerosol contributions and other originators. The uncertainty in the total aerosol forcings (i.e. $\pm 0.70 \mathrm{~W} / \mathrm{m}^{2}$ ) dominates the total error budget of the Earth's energy balance. The cross-hatched bars represent forcings addressed by FAST.

This paper will first provide an introduction to atmospheric aerosols and then address past, current and future missions devoted to their characterization. Then it will outline the FAST mission with emphasis on the scientific payload. Finally, it will address the potentials and challenges of the FAST mission for atmospheric research and its implications for climate modeling.

\section{AEROSOL CHARACTERIZATION}

This chapter provides an introduction into aerosol properties, their effects, and ways to detect and characterize aerosols. Furthermore it describes selected past, current and future space mission which can characterize atmospheric aerosols.

\section{Aerosol Properties}

Aerosols are suspensions of fine solid or liquid droplets in a gas. Primary types of terrestrial aerosols are oceanic sea alt, desert dust, volcanic ashes and volcanic sulfuric acid and various types of anthropogenic aerosols. Examples of the latter are biomass burning smoke, industrial smoke and soot and industrial sulfate. Cloud water and ice are not subsumed under aerosols.

So-called primary aerosol particles are directly emitted into the atmosphere by combustion sources or other wind-driven processes. Secondary aerosol particles are generated from photochemical reactions of gases which form new particles or condense on existing particles. An example of secondary particles is the secondary organic aerosol (SOA) which originates from oxidized gas-phase organics that condense on particle surfaces.

The effective height of the aerosol atmosphere varies in different spectral bands, i.e. it depends on the observational wavelength. It is maximum in the visible spectrum with typical values of $1 \mathrm{~km}$ and has a minimum close to a wavelength ${ }^{1}$ of $1 \mu \mathrm{m}$. The size of aerosol particles ${ }^{2}$ can range from about 0.001 to $100 \mu \mathrm{m}$. Submicrometer particles comprise primarily carbonaceous species as well as inorganic species such as metals, sulfate, nitrate, and ammonium. Supermicrometer particles are usually inorganic species such as sea salt and dust and are composed mostly of transition metals, silicates, and alkali metals ${ }^{3,4}$. While liquid aerosols will be spherical, solid aerosols will have irregular shapes which depend on their composition and their formation process.

Most aerosol particles reside in the lower layers of the Earth's atmosphere, i.e. in the so-called boundary layer, which is the lowest part of the troposphere. The upper limit of the boundary layer varies in altitude and time, but is usually found around $1 \mathrm{~km}$. Higher atmospheric layers also contain aerosol particles. In particular, typical stratospheric aerosol particles are sulfuric acid particles originating from large volcanic eruptions.

On a short timescale, tropospheric aerosol removal takes place through sedimentation, rainfall cleansing etc. within about one week ${ }^{5}$. Recent evaluations of long-term satellite records suggest a decreasing global aerosol optical thickness ${ }^{6}$.

\section{Effects of Aerosols}

Aerosol particles can have significant effects on air quality and human health; notorious examples are fine dust particles. Aerosol particles are most famous, however, because of their effects on visibility, the weather, and the climate. Aerosols affect the climate through:

1. scattering and absorption of solar radiation,

2. scattering, absorption and emission of thermal radiation, 
Tab. 1 Selected past and current space missions and instruments contributing to aerosol characterization. In case of different values, the maximum nadir resolution and the average power has been used.

\begin{tabular}{|c|c|c|c|c|c|c|c|c|c|}
\hline Mission & Launch & Instrument & Type & Prime purpose & Nadir resolution $[\mathrm{km}]$ & Wavelength [ [m] & Swath nadir $[\mathrm{km}]$ & Power [W] & $\frac{\text { Mass [kg] }}{36}$ \\
\hline TIROS-N & 1978 & AVHRR & Radiometer & Cloud and thermal emission & 1.1 & \begin{tabular}{|l}
$0.6-12.0$ \\
\end{tabular} & 2600 & 29 & 36 \\
\hline ERBS & 1984 & SAGE II & Photometer & Atmospheric chemistry and dynamics & n.a. & $0.4-1.0$ & n.a. & 10 & 35 \\
\hline Earth Probe & 1996 & TOMS & Spectrometer & Ozone characterization & 47.0 & $0.3-0.4$ & 3000 & 25 & 34 \\
\hline Terra & 1999 & MISR & Spectroradiometer & Reflected sunlight and scenes characteristics & 0.3 & $0.5-0.9$ & 376 & 75 & 148 \\
\hline ODIN & 2001 & OSIRIS & Spectrograph & Altitude profiles of atmospheric minor species & n.a. & $0.3-0.8,1.3$ & n.a. & 17 & 12 \\
\hline ENVISAT & 2002 & SCIAMACHY & Spectrometer & Atmosphere radiance & 15.0 & $0.2-2.4$ & 1000 & 155 & 215 \\
\hline Aqua & 2002 & MODIS & Spectroradiometer & Earth's cloud cover, radiation budget & 0.3 & $0.4-14.4$ & 2330 & 163 & 229 \\
\hline EOS Aura & 2004 & OMI & Spectrometer & Ozone characterization & 13.0 & $0.3-0.5$ & 2600 & 66 & 65 \\
\hline Parasol & 2004 & POLDER & Radiometer & Earth's reflectances & 6 & $0.4-0.9$ & 2400 & 50 & 32 \\
\hline Calipso & 2006 & CALIOP & Lidar & Aerosol and cloud profiles & 0.3 & $0.5,1.1$ & 0.1 & 197 & 172 \\
\hline MetOp A & 2006 & AVHRR/3 & Radiometer & Cloud and thermal emission & 1.0 & $0.6-12.0$ & 2600 & 29 & 33 \\
\hline
\end{tabular}

3. acting as cloud condensation nuclei,

4. catalyzing chemical reactions.

The first two mechanisms are called the direct climate effect, and are also referred to as radiative forcing. The third effect is called the indirect effect and is generally referred to as indirect radiative forcing.

The direct effect from reflective tropospheric aerosols causes a negative forcing because they scatter sunlight back to space (cf. Fig. 1). In contrast, black carbon aerosols absorb solar energy followed by re-radiation of the absorbed energy at infrared wavelengths, causing a positive forcing. The negative forcing of the indirect aerosol effect (cf. Fig. 1) appears to be mainly due to an increase of cloud brightness, as aerosols increase the number and reduce the size of cloud droplets. This causes also more persistent cloud coverage since smaller droplets inhibit rainfall and increase the lifetime of clouds $^{8}$.

Aerosols cause a negative climate forcing with substantial uncertainties; the largest individual uncertainty coming from the indirect aerosol effect. The Intergovernmental Panel on Climate Change (IPCC) has recently specified the global average forcings ${ }^{9}$ in 2005 with respect to 1750 for the direct effect as $-0.5 \pm 0.4 \mathrm{~W} / \mathrm{m}^{2}$ and that of the indirect effect as $-0.7(-1.8$ to -0.3$) \mathrm{W} / \mathrm{m}^{2}$.

Thus, aerosols play a significant and complex role in the Earth's climate. As seen from Fig. 1, the uncertainty in the total aerosol forcing is thought to dominate the overall error budget in the total climate forcing. Therefore it has recently been stated that current uncertainties in the aerosol forcing and the total solar irradiance are so large that they preclude meaningful climate model evaluation ${ }^{10}$. Clearly, current knowledge about atmospheric aerosol characteristics such as composition (refractive index), size, shape, and number density is lacking although a thorough understanding is vital for proper climate modelling.

\section{Detecting and characterizing aerosol}

Currently, three scientific approaches to study atmospheric aerosols are predominant: Field measurements, laboratory studies and modeling analysis ${ }^{4}$. Although atmospheric aerosols can be characterized by in-situ measurements (i.e. by sampling the particles), they are usually detected and characterized remotely by their interaction with radiation, for example by measuring the sunlight that has been scattered by them. These remote measurements can be performed from ground-based stations, from, e.g., airplanes or from remote-sensing satellites.

Measurements from the ground and also from airplanes are affected by local and regional industrial activities, traffic, surface cover, soil type, and winds and are inherently limited in their coverage in space and time. Depending on the orbit, satellite observations cover the whole Earth, albeit that with one satellite, it is difficult to capture local time variations.

Traditionally, only the flux of scattered sunlight is being measured. It appears, however, that the degree and direction of polarization of the scattered light is much more sensitive to the particle characteristics, i.e. size, shape and composition than the flux is ${ }^{11}$ (cf. Fig. 2). Both the flux and the polarization of light scattered by a given type of particles depend strongly on the scattering angle (see Figs. 2 and 5) and on the wavelength. In particular, this angle and wavelength variation of the flux and polarization enables one to retrieve the particle properties.

\section{Past and Current Space Missions}

Detection and characterization of aerosols from space was first done with the Advanced Very High Resolution Radiometer (AVHRR) as early as 1978. The instrument has been flown on 15 missions, the last one in a third version from 2006 onwards on MetOp $A^{12}$. The Stratospheric Aerosol and Gas Experiment 2 (SAGE II) used a seven-channel Sun photometer to determine the chemistry and dynamic motions of the Earth's upper troposphere and stratosphere from 10 to 40 kilometers $^{13}$. The Total Ozone Mapping Spectrometer (TOMS) was a successful instrument which flew on four spacecraft starting with Nimbus 7 in 1978 and ending in 2006 with the Earth Probe spacecraft ${ }^{14}$. The Multi-angle Imaging Spectroradiometer (MISR) measured the angular variation of reflected sunlight using nine different angles and 36 spectral channels ${ }^{15}$. 
OSIRIS (Optical Spectropgraph and InfraRed Imager Systems) performs limb scans of transmitted sunlight with a three-channel infrared imager ${ }^{16}$ from which altitude profiles are retrieved. SCIAMACHY (Scanning Imaging Absorption spectroMeter for Atmospheric CartograpHY) measures the flux of reflected sunlight in the nadir direction and transmitted sunlight in limb view from the ultra-violet to the near infrared ${ }^{17}$.

The POLDER (POLarization and Directionality of the Earth's Reflectances) instrument was the first instrument to measure both the flux and the polarization of aerosols from space. It measures the sunlight scattered by aerosols and reflected by the surface in three spectral bands $440 \mathrm{~nm}$, $670 \mathrm{~nm}$, and $865 \mathrm{~nm}^{18,19}$. POLDER consists of a camera composed of a two-dimensional CCD detector array, wide field-of-view telecentric optics and a rotating filter wheel carrying spectral and polarized filters some of which are polarizers. Because of the time difference between these measurements, the error in the polarization is about $2 \%$, which is rather large ${ }^{11}$. In addition, there is no simultaneous data in different wavelength bands. Polder instruments have been payloads on the ADEOS I and II and Parasol spacecraft which were launched 1996, 2002, and 2004, respectively.

The Moderate Resolution Imaging Spectroradiometer (MODIS) observes the Earth's clouds in 36 channels $^{20}$. The Ozone Monitoring Instrument (OMI) continues the TOMS series of instruments using a wide-field telescope feeding two imaging grating hyperspectral spectrometers. OMI is one of four scientific instruments on the Aura spacecraft which forms part of the A-train ${ }^{21}$. The A-train is a distributed space system comprising the Aqua, CloudSat, Calipso, Parasol and Aura spacecraft which allows for a synoptic evaluation of payload data for atmospheric research. On Calipso, the French Cloud-Aerosol Lidar with Orthogonal Polarization (CALIOP) provides aerosol and cloud profiles using a two-channel polarized lidarr $^{22}$, where the depolarization of the backscattered lidar beam gives information about the phase of the particles.

\section{Future Missions}

NASA's upcoming Glory mission will measure both the flux and polarisation of scattered sunlight at nine wavelength bands $(410,443$, $555,670,865,910,1370,1610$, and $2200 \mathrm{~nm}$ ) using the APS (Aerosol Polarimetry Sensor) instrument ${ }^{10}$. Like with POLDER, measurements in different wavelength bands are taken at different times. With APS, the degree of polarization of the scattered sunlight is determined from three separate measurements

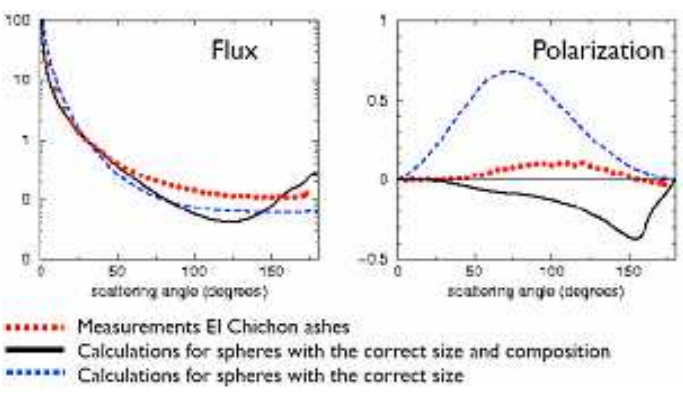

Fig. 2 Flux [\%] (left) and degree of linear polarization [-] (right) for measured and simulated particles as a function of the scattering angle. Note the weak (strong) sensitivity of the composition on flux (polarization) ${ }^{2,23}$.

through three separate polarizers. Unlike with POLDER, however, the three measurements are taken simultaneously, on three separate detectors, through APS' three telescopes. With this approach, the polarization error due to timing is caught, however, the different sets of optics will introduce other errors. Another disadvantage of the triple optics is that APS has a high mass of $58 \mathrm{~kg}^{10}$.

The EarthCARE (Earth Clouds, Aerosols and Radiation Explorer) mission is part of ESA's Earth Observation Living Planet Program and is ESA's $6^{\text {th }}$ Earth Explorer mission. It applies a synergetic approach to combine four main payloads on a single mission: a Cloud Profiling Radar (CPR), an atmospheric lidar (ATLID), a Multi-Spectral Imager (MSI), and a broad-band radiometer $(\mathrm{BBR})^{24}$. Both the active ATLID and the passive MSI contribute to aerosol

Tab. 2 Selected future space missions and instruments contributing to aerosol characterization.

\begin{tabular}{|l|c|c|c|c|r|}
\hline Mission & Launch & Instrument & Wavelength [ $[\mathrm{m}]$ & Swath nadir [km] & Mass [kg] \\
\hline Glory & 2008 & APS & $0.4-2.2$ & 5.6 & 58 \\
\hline FAST & 2011 & SPEX & $0.4-0.8$ & 73 & 5 \\
\hline FAST & 2011 & SILAT & 0.5 & 0.03 & 7 \\
\hline EarthCARE & 2013 & MSI & $0.7-12.0$ & 150 & 15 \\
\hline EarthCARE & 2013 & ATLID & 0.4 & 0.03 & 230 \\
\hline
\end{tabular}

characterization. MSI will measure the flux of scattered sunlight in four spectral bands $(0.67$, $0.865,1.65,2.21 \mu \mathrm{m})$ and thermally emitted fluxes in three spectral bands $(8.8,10.8$, $12.0 \mu \mathrm{m})$. ATLID is a single channel lidar operating in the ultra-violet with a high spectral resolution receiver using a small laser beam footprint of about $6 \mathrm{~m}$ combined with a small telescope footprint of about $30 \mathrm{~m}$.

Even though both APS and POLDER measure flux and polarization, they do so only in one spectral band at a time, and, especially in the case of POLDER, with relatively large errors. SPEX (Spectropolarimeter for Planetary Exploration), a small, innovative instrument currently under development in the Netherlands, measures flux and polarization across a broad wavelength region (400-800 $\mathrm{nm}$ ) with a spectral resolution of about $2 \mathrm{~nm}$. To achieve this, it has 
only one detector and no moving parts ${ }^{25,26}$. The instrument is compact enough to fit on a microsatellite, allowing low-cost and fast access to space. SPEX is planned to be flown on the FAST mission. Both the FAST mission as well as its scientific payload is described in detail in the next section.

\section{FAST MISSION}

FAST is a cooperation between the Delft University of Technology, The Netherlands, and the Tsinghua University of Beijing, China. The goal is to jointly define, develop and operate the FAST mission using two micro-satellites flying in formation to cover scientific, technological and educational objectives alike.

The FAST mission has three equally important top level objectives, namely:

1. Characterize atmospheric aerosols, monitor variation of height profiles in the cryosphere, and correlate these data for improved science return.

2. Demonstrate autonomous formation flying (AFF) using various communication architectures with distributed propulsion systems and MEMS technology.

3. Teach cutting-edge technology, broaden international view of students and boost skills through exchange of students and staff.

The space segment of the mission consists of two micro-satellites flying in formation: one developed in Delft (FAST-D) and one developed in Beijing (FAST-T). Both spacecraft will carry the SPEX instrument as well as an altimeter.

The baseline orbit for the two satellites is a sunsynchronous orbit (SSO) at $650 \mathrm{~km}$ altitude. The space segment will have an open architecture, i.e. complementary satellites from other nations or institutions can join the formation or train in the future. This makes FAST the kernel of the first micro-satellite train in space.

The mission timeline will consist out of two primary modes, each lasting one year. In mode $A$, the satellites will fly in formation with an along-track separation ranging from $1 \pm 0.1 \mathrm{~km}$ to $900 \pm 10 \mathrm{~km}$ for AFF technology demonstration and for optimal SPEX science data return. In mode $B$, the separation between the satellites will be increased substantially to a train configuration in order to measure changes in aerosol characteristics at certain locations over several hours. The separation of the two spacecraft in mode $B$ is a trade off between propellant usage, manoeuvre time and required temporal separation.

\section{Spacecraft}

FAST-D will carry two scientific payloads, namely SPEX and a miniature laser altimeter called SILAT (Stereo Imaging Laser Altimeter). The combined mass of the two payloads is less than $13 \mathrm{~kg}$. The total mass of FAST-D is expected to be $35 \mathrm{~kg}$, with peak power requirement of $45 \mathrm{~W}$.

FAST-D will be equipped with a radio-frequency (RF) inter-satellite link which is capable of transmitting data and measuring the distance to FAST-T. A GNSS receiver will provide absolute position and velocity data.

The Chinese spacecraft FAST-T will be based on the Tsinghua-2 spacecraft design which is currently under development. Its scientific payloads are SPEX and a radar altimeter. The combined mass of the two payloads is less than $25 \mathrm{~kg}$ and the total spacecraft mass is expected to be $80 \mathrm{~kg}$. The power requirement is estimated at $80 \mathrm{~W}$, which calls for a deployable solar array. There is the possibility for one additional payload to increase environmental data return.

\section{Payload}

Three primary payload types will be flown: the SPEX spectropolarimeter on FAST-D and FAST-T, the SILAT laser altimeter on FAST-D and a radar altimeter on FAST-T. SPEX and SILAT are described in detail in the following.

\section{SPEX}

This spectropolarimeter is currently under development by a consortium of Dutch entities consisting of Dutch Space, TNO, SRON Netherlands Institute for Space Research, the Netherlands Foundation for Research in Astronomy (ASTRON), and the Astronomy Department of the University of Utrecht. The instrument is primarily intended for planetary exploration but can be adapted for an Earth observation mission.

Since the instrument is intended particularly for a Mars mission, cost, and thus mass, constraints drove the specification for the total instrument mass to less than $5 \mathrm{~kg}$. Furthermore, low power consumption and high reliability are required. This has resulted in a completely mechanismsfree design excluding e.g. scanning mirrors. A drawback of this design is the limited swath width, as shown in Tab. 3.

Table 3. SPEX key characteristics ${ }^{27}$.

\begin{tabular}{|l|l|}
\hline Wavelength range & $400-800 \mathrm{~nm}$ \\
\hline Spectral resolution & better than $2 \mathrm{~nm}$ \\
\hline Spectral sampling & 2 detector pixels \\
\hline Spatial resolution & $19 \mathrm{~km} @$ nadir from $650 \mathrm{~km}$ \\
\hline Viewing directions & $\begin{array}{l}0^{\circ} \pm 18^{\circ} \pm 36^{\circ}, \pm 54^{\circ}, \text { limb } \\
\text { forward and backward view }\end{array}$ \\
\hline $\begin{array}{l}\text { FOV per viewing } \\
\text { direction }\end{array}$ & $\begin{array}{l}791.7^{\circ} \text { (cross track } \times \text { along } \\
\text { track) }\end{array}$ \\
\hline $\begin{array}{l}\text { Mass (excl. } \\
\text { electronics, thermal) }\end{array}$ & $2 \mathrm{~kg}$ (target) \\
\hline $\begin{array}{l}\text { Form factor SPEX } \\
\text { subsystem }\end{array}$ & $130 \times 130 \times 60 \mathrm{~mm}^{3}$ \\
\hline
\end{tabular}




\begin{tabular}{|l|lr|}
\hline Power requirement & \multicolumn{2}{|l|}{ CMOS detector: <0.5 W } \\
\hline $\begin{array}{l}\text { Operational } \\
\text { constraints }\end{array}$ & $\begin{array}{l}\text { Pointing knowledge and } \\
\text { stability of platform smaller } \\
\text { than 360". }\end{array}$ \\
\hline $\begin{array}{l}\text { Data rate for } 650 \mathrm{~km} \\
\text { SSO orbit }\end{array}$ & $\begin{array}{l}16.6 \quad \text { Gbit/day } \\
\text { compression) }\end{array}$ \\
\hline Data storage & Spacecraft OBDH \\
\hline
\end{tabular}

The instrument baseline specification has seven downward viewing directions along the flight direction (at $0^{\circ}, \pm 18^{\circ}, \pm 36^{\circ}$, and $\pm 54^{\circ}$ with respect to the vertical direction, cf. Fig. 7), and two (forward and backward) limb viewing directions. The viewing angles are chosen such that the scattering angle dependence of the flux and polarization of the scattered sunlight is sufficiently sampled (cf. Fig. 2). The optimal sampling will be obtained for intermediate to large phase angles (cf. Fig. 5).

SPEX has a truly innovative method for doing polarimetry: the degree and direction of linear polarization of the scattered and observed sunlight is encoded as a sinusoidal modulation into the flux spectrum ${ }^{25,26}$. Thus, from a single flux spectrum (measured in a specific viewing direction), the spectral dependence of the polarization and the flux itself can be retrieved. The spectral measurements in the various viewing directions are thus performed simultaneously.

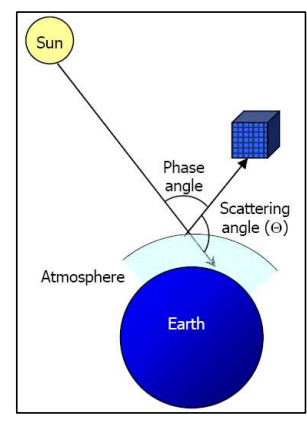

Fig. 5. Definition of the scattering angle.

\section{SILAT}

The Stereo Imaging Laser Altimeter (SILAT) is currently under development at cosine Research B.V. in Leiden, The Netherlands, and was initially intended to fly on ESA's Mercury mission (BepiColombo). The current design is based on a Europa mission (Tab. 4) and can be adapted for an Earth observation mission with an expected decrease in mass.

SILAT is an example of a highly integrated payload where three different instruments are combined to create a new instrument with superior characteristics than all three instruments separately. It consists firstly of a miniature laser altimeter (LAT) that employs photon counting to measure height variations. Secondly, there is a high resolution camera
(HRC) that can make detailed colour pictures of the planet surface. Thirdly, together with a stereoscopic forward looking camera (SCAM), this allows the creation of accurate three dimensional maps of the planet surface.

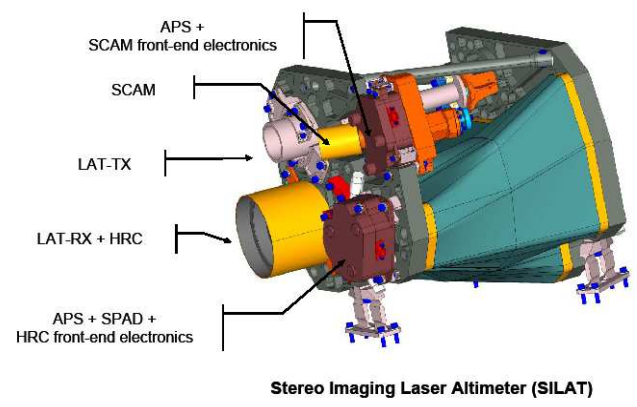

Figure 6. Mechanical layout of SILAT. The laser emitter (LAT-TX) is located next to the combined High Resolution Colour Camera (HRC) and the laser receiver (LAT-RX) TMA (Three Mirror Anastigmatic) optics. Both HRC and SCAM (stereoscopic forward looking camera) use miniaturized front-end electronics and a CMOS Active Pixel Sensor (APS). The laser light detector, a Single Photon Avalanche Diode (SPAD), is integrated in the HRC focal plane. The main electronics unit including the data processing unit and the power supplies is not shown ${ }^{28}$.

Table 4. SILAT key characteristics ${ }^{29}$ based on an instrument design for a Europa mission.

\begin{tabular}{|c|c|}
\hline \multicolumn{2}{|c|}{ Overall } \\
\hline Total mass $[\mathrm{kg}]$ & 7.77 \\
\hline Dimensions $\left[\mathrm{mm}^{3}\right]$ & $287 \times 327 \times 327$ \\
\hline Power consumption [W] & 11.92 \\
\hline Temperature range $[\mathrm{K}]$ & $263-303$ \\
\hline $\begin{array}{l}\text { Platform pointing } \\
\text { accuracy required ["] }\end{array}$ & $24(\mathrm{TBC})$ \\
\hline $\begin{array}{l}\text { Platform pointing } \\
\text { stability required [“/ms] }\end{array}$ & $0.17(\mathrm{TBC})$ \\
\hline $\begin{array}{l}\text { Data rate for } 650 \mathrm{~km} \\
\text { SSO orbit }[\mathrm{Mbit} / \mathrm{s}]\end{array}$ & $\begin{array}{l}30.7 \text { (no compression, } \\
100 \% \text { duty cycle) }\end{array}$ \\
\hline \multicolumn{2}{|c|}{ LAT } \\
\hline Power consumption [W] & 10.34 \\
\hline Vertical resolution [m] & 0.15 \\
\hline Repetition freq. $[\mathrm{Hz}]$ & 10000 \\
\hline Wavelength $[\mathrm{nm}]$ & 532 \\
\hline Emitter FOV [rad] & 0.000050 \\
\hline Receiver FOV [rad] & 0.000150 \\
\hline Detector type & $\begin{array}{l}\text { Single Photon } \\
\text { Avalanche Diode }\end{array}$ \\
\hline \multicolumn{2}{|c|}{ HRC } \\
\hline Power consumption [W] & 0.5 \\
\hline FOV [deg] & 3.7 \\
\hline IFOV [deg] & $0.0018(0.031 \mathrm{mrad})$ \\
\hline Sensor type & Active Pixel Sensor \\
\hline Filter configuration [nm] & $404,559,671$ \\
\hline Shutter time $[\mathrm{ms}]$ & 2.5 \\
\hline \multicolumn{2}{|c|}{ SCAM } \\
\hline Power consumption [W] & 1.076 \\
\hline Off nadir pointing [deg] & 27 \\
\hline FOV [deg] & 4.7 (TBC) \\
\hline IFOV [deg] & 0.0045 \\
\hline Sensor type & Active Pixel Sensor \\
\hline Filter configuration [nm] & 559 \\
\hline Shutter time $[\mathrm{ms}]$ & 6.3 \\
\hline
\end{tabular}

Paper IAC-08-B1.I.1, 59th International Astronautical Congress, September 29 - October 3 2008, Glasgow, Scotland 


\section{SCIENCE OPPORTUNITIES AND CHALLENGES}

Apart from the new science enabled by the individual instruments SPEX, SILAT and the radar altimeter, the FAST mission provides additional science opportunities. These stem from a synoptic evaluation of data from different instruments within the mission and from the distribution of these instruments on different platforms.

\section{Science from SPEX}

The spectropolarimeter SPEX measures the flux and polarization of sunlight that is scattered by atmospheric aerosols through seven surface pointing fixed-angle directions, or fields-of-views (FOVs). For a non-rotating Earth, SPEX would observe each location on Earth from seven different directions as it flies over it. However, as the Earth rotates underneath the satellites' orbit, a location on Earth that was fully in view for SPEX's most forward viewing direction will have rotated (partly) out of view of the nadir and especially of the backward viewing direction. This effect reduces the spatial overlap of the different FOVs and hence SPEX' spatial coverage.

This can be compensated through a second SPEX instrument flying at a separation of about $650 \mathrm{~km} \tan \left(54^{\circ}\right) \sim 894 \mathrm{~km}$ behind the first one (mode A of the mission) while keeping the simple attitude control law. An appropriate steering of the attitude to compensate for the Earth rotation is possible but has drawbacks.

This particular configuration is shown in Fig. 7 where the nadir swath of one SPEX instruments overlaps with the forward looking swath of the other instrument. Furthermore, in this configuration aerosol backscattering of the same region can be observed precisely at the same time at two different scattering angles which is not achievable with a single spacecraft mission. Note, that the field of views of the two instruments can, especially due to the flexible intersatellite separation, intersect at various angles and altitudes which can enable aerosol characterization at different altitudes.

The most relevant opportunity regarding science output from SPEX stems however from the wide range of spatial and temporal coverage which is provided by the formation. In the formation mode $\mathrm{A}$, a close intersatellite separation of $1 \mathrm{~km}$ allows for a temporal resolution of about $130 \mathrm{~ms}$ which opens up new possibilities to investigate shortterm dynamical processes of aerosols. In the train configuration of mode $\mathrm{B}$, the separation between the satellites can be up to several hours. This allows scientists to study, e.g., daily

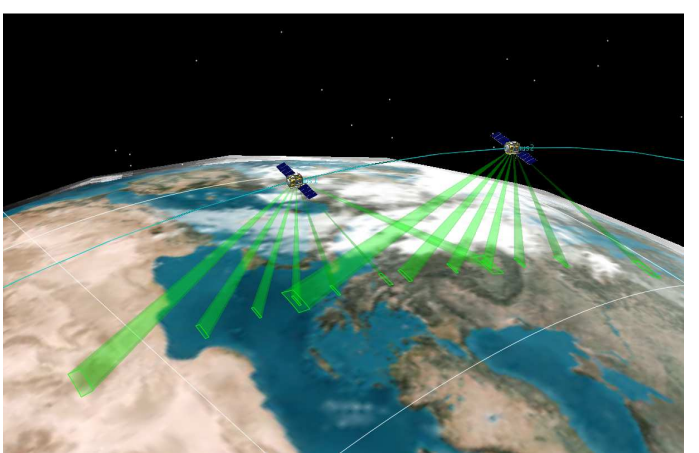

Figure 7. FAST-D and FAST-T in mode A, illustrating the overlapping field-of-views of SPEX ${ }^{30}$.

variations of aerosol properties over specific regions such as to monitor strongly polluted regions or natural disasters. Thus, depending on the mission phase and scientific needs, repetitive observation times can be adjusted between several hundred milliseconds to several hours.

The same flexibility is valid for the spatial coverage. Within, e.g., the A-train, each spacecraft has a fixed phase in a predefined orbital plane thus limiting the flexibility for temporal and spatial coverage. For FAST in the train mode, the relative right ascension of the ascending node and the mean anomaly can be changed such that essentially any two regions worldwide could be characterized at the same time. Finally, the effective swath of the instrument at a certain latitude can almost be doubled by flying the two spacecraft in close separation, each spacecraft performing an opposite roll steering of around $3.5^{\circ}$.

\section{Science output from altimeters}

The primary objective of the altimeters on the two spacecraft is to monitor seasonal changes in height profiles in the cryosphere. However, different altimeter types will be flown on the two spacecraft: FAST-T will employ a Chinese radar altimeter, while FAST-D will employ the miniature Dutch laser altimeter SILAT. This opens up several unique science opportunities. From an instrument technology point of view, the data types can be used for cross-calibration and comparison of two fundamentally different altimeter types at almost the same measurement time and location. Furthermore, the combination of a laser and a radar altimeter offers the potential of directly measuring snow thickness on ice since radar waves will penetrate snow and be reflected by the ice while light waves will be reflected by the snow. Using a laser and a radar altimeter, clouds can be detected since radar waves are unobstructed by clouds while light is reflected. 


\section{Combined altimeter and SPEX science}

Next to separate SPEX and altimeter science, the data can be evaluated in a combined process exploiting the synergies between the data types. The correlation of altimeter data with aerosol measurements made by SPEX provides the opportunity to study the influence of aerosols on ice and snow. As an example, SCAM can, in principle, be pointed to the same direction as one of the SPEX channels supporting the analysis of aerosol data. The combination of SPEX, SILAT, and the radar altimeter allows for combined aerosol and cloud data retrieval, which is highly relevant as aerosols influence cloud formation to a large extent. A similar strategy will also be applied with the A-train formation where the combination of Glory's APS, the CALIPSO lidar, and the CloudSat radar will provide similar data ${ }^{10}$. Most important however, in terms of additional scientific and environmental value, is the ability that the combination of SPEX, SILAT, and the radar altimeter will allow an improved characterization of the indirect aerosol forcing which is currently the most uncertain contribution in the climate forcing budget.

\section{Challenges}

The FAST mission holds programmatic, scientific and technologic challenges. The major challenge is to generate scientifically relevant output taking into account constraints from the micro-satellite platforms and the academic environment.

So far, atmospheric science from space has primarily been based on payload flown on large to mini satellites. Miniaturization is, however, affecting both the spacecraft bus and the payload which enables less-massive spacecraft to achieve similar or even more advanced mission objectives. The FAST-D payload suite comprises four sensors integrated in two instruments with a total payload mass of less than $13 \mathrm{~kg}$. The targeted total spacecraft mass of FAST-D of $35 \mathrm{~kg}$ makes the design of the subsystems particularly challenging. The attitude control system (ACS) has been found to be the most challenging sub-system for FAST.

FAST will be one of the first formation flying missions based on micro-satellites which address ambitious scientific objectives. The challenge of flying two SPEX instruments in formation is related to relative attitude control, spacecraft operations and joint science data evaluation on-ground. However, due to the limited ground resolution of the SPEX instrument, the absolute and relative attitude control is feasible. The coordinated control of the formation can safely be conducted using ground-in-the-loop for separations of more than
$10 \mathrm{~km}$. For closer configurations, especially for separations below $1 \mathrm{~km}$, autonomous formation flying becomes inevitable. The common evaluation of science data on-ground, requiring co-registration, time tagging, consistent preprocessing and synchronization with auxiliary flight data, is a tremendous challenge in itself.

\section{SUMMARY AND CONCLUSIONS}

The uncertainty in the aerosol indirect radiative forcing due to aerosols is the largest single error source which affects our ability to model and predict climate change. FAST, a formation flying mission of two micro-satellites, will allow to characterize the direct and indirect radiative effect of aerosols and to measure climate change indicators in a single mission. The mission foresees two spectropolarimeters and two types of altimeters to be flown in a sunsynchronous orbit for a mission duration of two years. This will allow an unprecedented characterization of flux and polarization states from aerosols in the Earth's atmosphere in terms of spectral resolution and spatial and temporal coverage.

\section{REFERENCES}

1. Uzhegov V.N., Kabanov D.M., Panchenko M.V., Pkhalagov Y.A., Sakerin S.M.; About "Effective" Height of the Aerosol Atmosphere in Visible and IR Wavelength Range; Fourteenth ARM Science Team Meeting Proceedings, Albuquerque, New Mexico, March 22-26 (2004).

2. Stam D.M.; Atmospheric Research with Microsats, Presentation, Delft, The Netherlands, February 12 , (2008).

3. Noble C.A., Prather K.A.; Real-time measurement of correlated size and composition profiles of individual atmospheric aerosol particles; Environ. Sci. Technol. 30:2667-80 (1996).

4. Prather K.A., Hatch C.D., Grassian V.H.; Analysis of Atmospheric Aerosols; Annu. Rev. Anal. Chem. 1, 485-514 (2008).

5. Seinfeld J. H., Pandis S. N.; Atmospheric Chemistry and Physics: From Air Pollution to Climate Change; John Wiley and Sons, 1326 (1997).

6. Mishchenko M.I., Geogdzhayev I.V., Rossow W.B., Cairns B., Carlson B.E., Lacis A.A., Liu L., Travis L.D.; Long-Term Satellite Record Reveals Likely Recent Aerosol Trend; Science, 315, 1543, (2007).

7. Hansen J., Nazarenko L., Ruedy R., Sato M., Willis J., Genio A.D., Koch D., Lacis A., Lo K., Menon S., Novakov T., Perlwitz J., Russell G., Schmidt G.A., Tausnev N.; Earth's Energy Imbalance: Confirmation and Implications; Science 308, 1431 (2005).

8. Hansen J., Sato M., Ruedy R., Lacis A., Oinas V.; Global warming in the twenty-first century: An 
alternative scenario, Proceedings of the National Academy of Sciences of the United States of America, 97, 18, 9875-9880, August 29, 2000.

9. Forster, P., Ramaswamy V., Artaxo P., Berntsen T., Betts R., Fahey D.W., Haywood J., Lean J., Lowe D.C., Myhre G., Nganga J., Prinn R., Raga G., Schulz M., Van Dorland R.; Changes in Atmospheric Constituents and in Radiative Forcing. In: Climate Change 2007: The Physical Science Basis; Contribution of Working Group I to the Fourth Assessment Report of the Intergovernmental Panel on Climate Change; Solomon, S., D. Qin, M. Manning, Z. Chen, M. Marquis, K.B. Averyt, M.Tignor and H.L. Miller (eds.); Cambridge University Press, Cambridge, United Kingdom and New York, NY, USA (2007).

10. Mishchenko M.I., Cairns B., Kopp G., Schueler C.F., Fafaul B.A., Hansen J.E., Hooker R.J., Itchkawich T., Maring H.B., Travis L.D.; Accurate Monitoring of Terrestrial Aerosols and Total Solar Irradiance: Introducing the Glory Mission; Bulletin of the American Meteorological Society, 88, 5, 677-691, May (2007).

11. Mishchenko M.I., Travis L.D.; Satellite retrieval of aerosol properties over the ocean using polarization as well as intensity of reflected sunlight; J. Geophys. Res. 102, 16989-17014 (1997).

12. Advanced Very High Resolution Radiometer AVHRR; noaasis.noaa.gov/NOAASIS/ml /avhrr.html; last visited 2008/07/14.

13. Russell P.B., McCormick M.P.; SAGE // Aerosol Data Validation And Initial Data Use: An Introduction And Overview, J. Geophys. Res. 94, 8335-8338 (1989).

14. Torres O., Bhartia P.K., Herman J.R., Sinyuk A., Holben B.; A long term record of aerosol optical thickness from TOMS observations and comparison to AERONET measurements, J. Atm. Sci., 59, 398-413 (2002).

15. Diner D.J.; Performance of the MISR Instrument During lts First 20 Months in Earth Orbit; IEEE TRANSACTIONS ON GEOSCIENCE AND REMOTE SENSING, 40, 7, 1449 (2002).

16. Llewellyn E., N. Lloyd, D. Degenstein, R. Gattinger, S. Petelina, A. Bourassa, J. Wiensz, E. Ivanov, I. McDade, B. Solheim, J. McConnell, C. Haley, C. von Savigny, C. Sioris, C. McLinden, E. Griffioen, J. Kaminski, W. Evans, E. Puckrin, K. Strong, V. Wehrle, R. Hum, D. Kendall, J. Matsushita, D. Murtagh, S. Brohede, J. Stegman, G. Witt, G. Barnes, W. Payne, L. Pich, K. Smith, G. Warshaw, D.-L. Deslauniers, P. Marchand, E. Richardson, R. King, I. Wevers, W. McCreath, E. Kyrl, L. Oikarinen, G. Leppelmeier, H. Auvinen, G. Mgie, A. Hauchecorne, F. Lefvre, J. de La Ne, P. Ricaud, U. Frisk, F. Sjoberg, F. von Schele, , and L. Nordh. The OSIRIS instrument on the Odin spacecraft. Can. J. Phys., 82, 6, 411-422 (2004).

17. Kaiser J.W., Eichmann K.-U., Noel S., Wuttke b, J. Skupin M.W., von Savigny C., Rozanov A.V., Rozanov V.V., Bovensmann H., Burrows J.B.;
SCIAMACHY limb spectra; Advances in Space Research, 34, 715-720 (2004).

18. POLDER instrument, Technical Features, CNES, http://smsc.cnes.fr/POLDER/GP instrument.htm, ; last visited 2008/07/14.

19. Andre Y., Laherrère J.M., Bret-Dibat T., Jouret M., Martinuzzi J.M., Perbos J.; Instrumental concept and performances of the POLDER instrument; SPIE proceedings Infrared spaceborne remote sensing III, 2553, San Diego, CA (1995).

20. MODIS Instrument Specifications ; http://modis.gsfc.nasa.gov/about/specifications.ph p; last visited 2008/07/14.

21. Kelly A.C., Macie E.J.; THE A-TRAIN: NASA'S EARTH OBSERVING SYSTEM (EOS) SATELLITES AND OTHER EARTH OBSERVATION SATELLITES; Proceedings of the 4th IAA Symposium on Small Satellites for Earth Observation, Berlin, Germany (2003).

22. Winker D.M., Hunt W.H., McGill M.J.; Initial performance assessment of CALIOP. GEOPHYSICAL RESEARCH LETTERS, 34, L19803 (2007).

23. Volten $\mathrm{H}_{\text {., }}$ et al., The Amsterdam Light Scattering Database, http://www.astro.uva.nl/scatter/, last visited 2008/07/14

24. Wehr T., Ingmann P., Lajas D., Heliere A.; EarthCARE: Towards a Quantification of CloudAerosol-Radiation Interactions; American Meteorological Society; http://ams.confex.com lams/ (2008).

25. Laan E.; SPEX Interface Control Document for the FAST mission; Issue 0.2, TNO Science and Industry, The Netherlands, April 18, (2008).

26. Snik F., Karalidi Th., Keller C.U., Laan E., ter Horst R., Navarro R., Stam D.M., Aas Ch., de Vries J., Oomen G., Hoogeveen R.; SPEX - An inorbit spectropolarimeter for planetary exploration, SPIE Astronomical Telescopes and Instrumentation, Marseille, 23-28 June (2008).

27. Laan E.; Specsheet for SPEX - Spectropolarimeter for Planetary Exploration, TNO Science and Industry, The Netherlands, November 12, (2007).

28. Kraft S., et al.; Demonstration of Highly Integrated Payload Architectures and Instrumentation for future planetary Missions, Proceedings of SPIE 5978-23, Remote Sensing Europe, Brugge (2005).

29. Moon S.; Specsheet SILAT, Issue 0.2, FAST Internal document, cosine research, Leiden, The Netherlands, May 15, (2008).

30. Maessen D.C., Gill E., Verhoeven C.J.M., Zheng G.T.; Preliminary Design of the Dutch-Chinese FAST Micro-Satellite Mission; Small Satellites Systems and Services - the 4S Symposium, Rhodes, Greece, 26-30 May (2008). 